\title{
Instructional design of problem-based teaching in Optical System Design course using informatization teaching resources
}

Yifan Huang, Qun Hao, Lin Li

Yifan Huang, Qun Hao, Lin Li, "Instructional design of problem-based teaching in Optical System Design course using informatization teaching resources," Proc. SPIE 11143, Fifteenth Conference on Education and Training in Optics and Photonics: ETOP 2019, 1114311 (2 July 2019); doi: $10.1117 / 12.2523848$

SPIE Event: Fifteenth Conference on Education and Training in Optics and Photonics: ETOP 2019, 2019, Quebec City, Quebec, Canada 


\title{
Instructional Design of Problem-based teaching in Optical system Design Course using informatization teaching resources
}

\author{
Yifan Huang*, Qun Hao, Lin Li \\ School of Optics and Photonics, Beijing Institute of Technology \\ 5\# Zhongguancun south street, Beijing ,CHINA
}

\begin{abstract}
Aiming to solve the contradiction between the problem-based teaching and limited class hours in engineering courses, an instructional design of Optical System Design course using informatization teaching resources is introduced in this paper. By using a massive open online course(MOOC) and other informatization teaching method, students can learn the basic knowledge and methods after class by themselves, while the class hours can be mainly used to face-to-face problem-discussing between teachers and students as well as among students themselves. In this way, the class is extended profitably. The students' potential were well stimulated. With the application of informatization methods, the problem-based teaching and learning can be carried out more efficiently.
\end{abstract}

Keywords: Problem-based teaching and learning, informatization teaching, instructional design, Massive open online course

\section{INTRODUCTION}

Engineering courses in higher education always aim to increase the students' abilities of solving practical problems. Problem-based teaching(PBT) and learning(PBL) methods have been proved to be effective ways to realize such a goal. By transforming knowledge transfer through traditional lecture-based teaching to improve the students' real-world problem solving ability, PBT and PBL have become the favored pedagogical model for technical courses.

But due to the limited class hours, it is difficult to fully implement these methods in traditional teaching mode, especially in Chinese universities which always has large numbers of students.

In recent years, with the rapidly popularization and development of the information technology, informatization has been a trend in education. Lots of online teaching resources have been established. Compared with traditional lecturebased teaching, informatization teaching has dominant advantages in abundant teaching resources, multimedia and easy interaction between teachers and students. Based on student-centered environment, students can be highly motivated.

However, when learning through informatization resources online, the students should always be self-disciplined and motivated, well organized and having high degree of time management skills. For more dependent learners, it is difficult for them assuming responsibilities required by the online courses. In addition, while hands-on practical capacity is involved, only learning from informatization online resources are powerless. In these case, traditional face-to-face course can maintain a fluid and solid learning process.

So we can see both modes have their own advantages and disadvantages. In order to maximize their effectiveness, we need to find a good balance. The key points to apply the informatization to the traditional education appropriately involve integrating the instructional resources, media, teachers, instructional methods, instructional strategies.

In this paper, we will discuss how we integrated the informatization teaching into the Optical System Design(OSD) course. The following section of this paper is: Section 2 is the course description. Section 3 will be the implementation methods of using informatization teaching mode. And we conclude our work in Section 4.

*huangyifan@bit.edu.cn; 861068913627

Fifteenth Conference on Education and Training in Optics and Photonics: ETOP 2019, edited by

Anne-Sophie Poulin-Girard, Joseph A. Shaw, Proc. of SPIE Vol. 11143, 1114311 - (C) 2019

SPIE, ICO, IEEE, OSA · CCC code: 0277-786X/19/\$18 · doi: 10.1117/12.2523848 


\section{ABOUT OPTICAL SYSTEM DESIGN COURSE}

\subsection{Course Objectives}

Optical System Design(OSD) is a professional course for undergraduate students at School of Optics and Photonics, Beijing Institute of Technology, CHINA. The objective of this course is to familiarize students with methods to design optical systems. Methods of how to design typical optical systems, such as telescopes, microscopes and photographic lenses will be discussed by using optical design software such as Zemax in this course.

In all, the teaching philosophy of $O S D$ course is to train students in the following three aspects:

1. Knowledge: An excellent optical system designer must have a solid foundation of knowledge on aberration, optical design theoretical knowledge as well as mathematical optimization methods. In consideration of solving real-world open-ended problems, the integration of different disciplines into one product or system is essential, and this course is devoted to developing students these skills.

2. Capability: Capability of problem solution ability is the basic requirement for the optical design engineers. At the same time, soft skills such as teamwork, communication and leadership are also very important for them.

3. Scientific Literacy: Scientific Literacy is a combination of scientific cognition, scientific methods and scientific spirit. The cultivation of scientific literacy is a long-term process. In this course what are mainly emphasized are scientific attitude, scientific conscious and social responsibility when designing a system.

\subsection{Learning outcomes}

After completing this course, a student will be expected to get the abilities of:

1. Understanding the basic theories of optical system design.

2. Having the ability to analyze real-world optical system problems and make design proposal.

3. Proficiency in typical methods and progress of designing typical optical systems.

4. Gaining experience in optical manufacturing, alignment and testing.

5. Considering and working across disciplines (optics, mechanical, electronics, computer and software, etc.) on team work.

\subsection{Course contents}

Optical System Design is traditionally a lecture-lab course which will last for 13 weeks. Following the problem-based teaching/learning methods, several optical system design projects coming from real research works will be assigned at the first stage of the class. The students are assigned to teams and each team chooses one project to implement in about ten weeks. Table 1 shows several projects we offered last year.

Table 1. Real-world design projects

\begin{tabular}{|l|l|}
\hline No. & \\
\hline 1 & Super-wide angle monitoring system \\
\hline 2 & Projecting optical system to keep electromagnetic information from leaking \\
\hline 3 & Medical endoscope system \\
\hline 4 & Off-axis three mirror system \\
\hline 5 & Assisted landing system for helicopters \\
\hline
\end{tabular}

In order to implement the project design, the students will learn from the lecture part about the following contents:

1. Part one, introduction of the aberrations, the image quality evaluation criteria, which are the basic knowledge for design an optical system. 
2. Part two, the principle of automatic optical design.

3. Part three, the theories of the first order aberrations, which are very important for an optical designer.

4. Part four, the methods of designing typical optical systems such as telescope objectives, eyepieces, microscope objectives and photographic lenses. The methods of using software of Zemax are also discussed in this course.

The lab work will follow each lecture part. Each student is required to spent lab time to do optical system design by using optical design software.

The whole course schedule and content of each period are shown in Table 2.

Table 2. Course schedule of Optical System Design

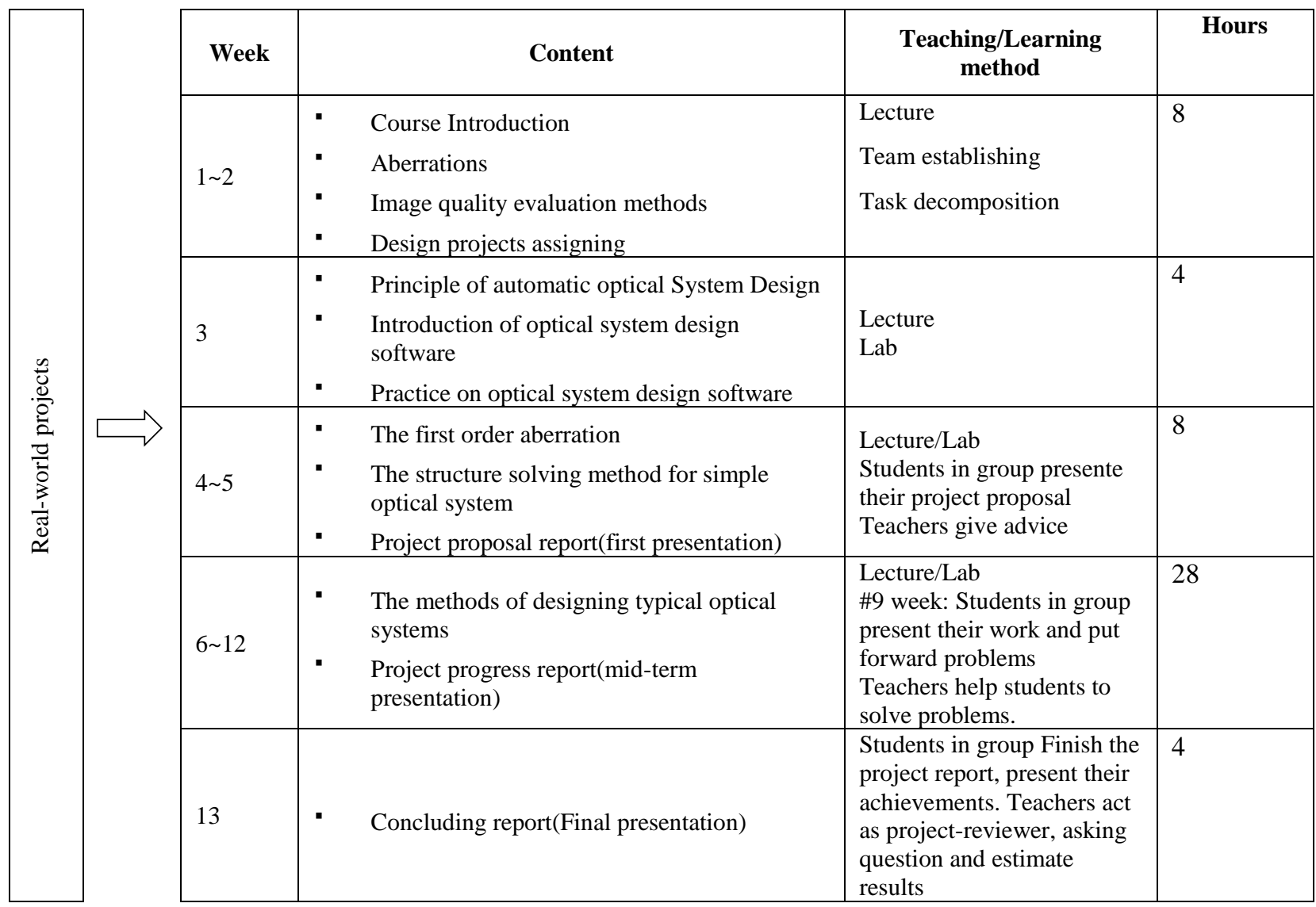

\subsection{Problems in OSD course}

Following this arrangement, Optical system design based on project-oriented principle has been implemented for 8 years. The real-world projects aroused students 'great interest in learning.

However, problems simultaneously emerged. We found that the contradiction between the limited class hours and more contents for project-oriented learning has been getting more and more obvious. For the students, they have to allocate about 48 class hours to learn the basic principle, software and to carry out their project design. They always complain they do not have enough time to design and to communicate with teachers. For the teachers, besides the regular teaching contents, they need to give the students adequate information about each project, the feasible and practical design method, the relevant engineering background and influencing factors. At the same time, teachers should make as much time as possible for the students to perform design. An even worse condition is that the numbers of students in a class will be 40-60. Every student will have his/her own questions. It is impossible for one teacher to answer all the students' different questions in the class. How to solve the problem brought by limited class hours? And how to meet different 
demands from students in the same period? These questions have led to the integration of informatization in our traditional teaching.

\section{INFORMATIZATION TEACHING IMPLEMENTATION}

\subsection{Informatization teaching resources}

In 2016, we began to establish the online teaching resources for Optical system design course. We made a massive open online course(MOOC). Considering different demand from different learners, we put the necessary but brief topics of optical system design in the online course, including both theories and practical design methods. Each content in the topics is an independent video about 15-30 minutes. Figure 1 shows some pictures from the videos.
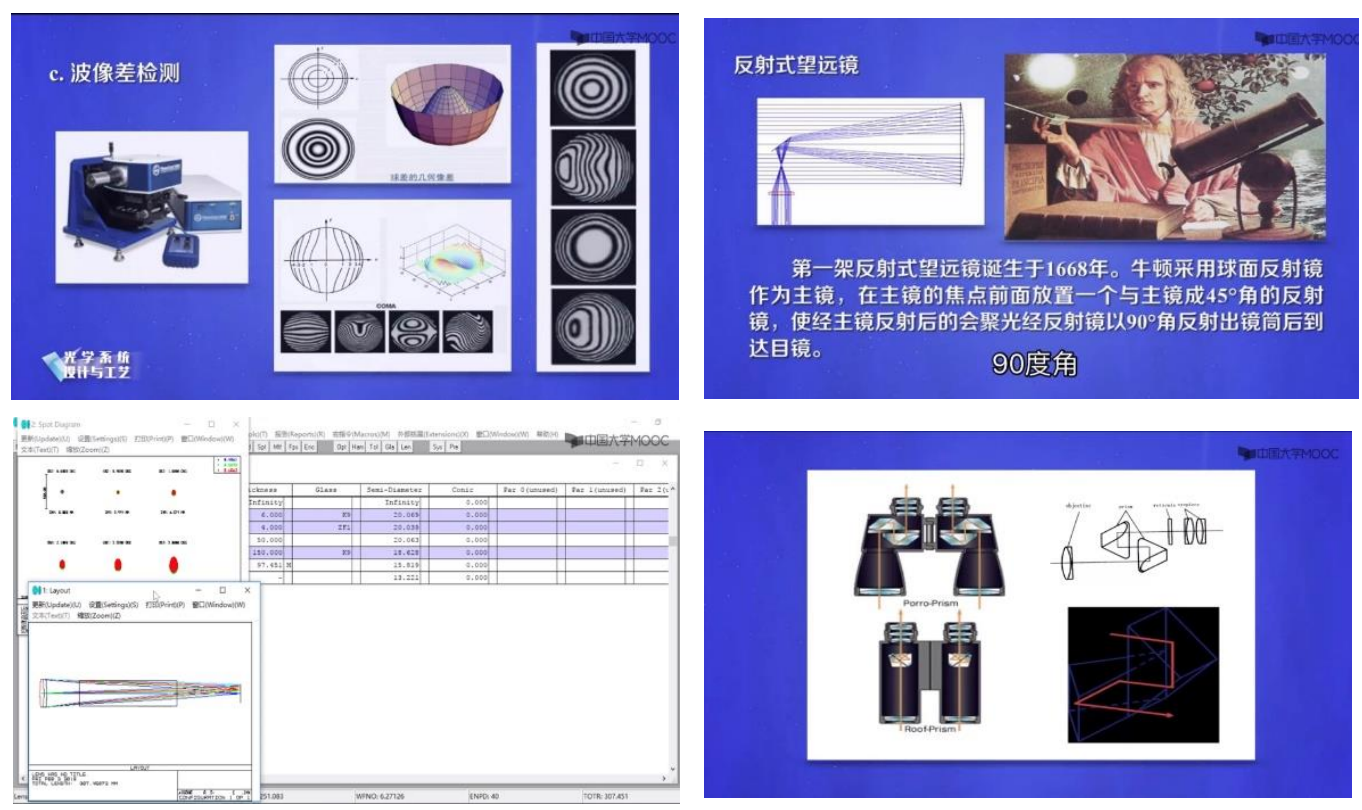

Figure 1. Picture of MOOC of Optical System Design

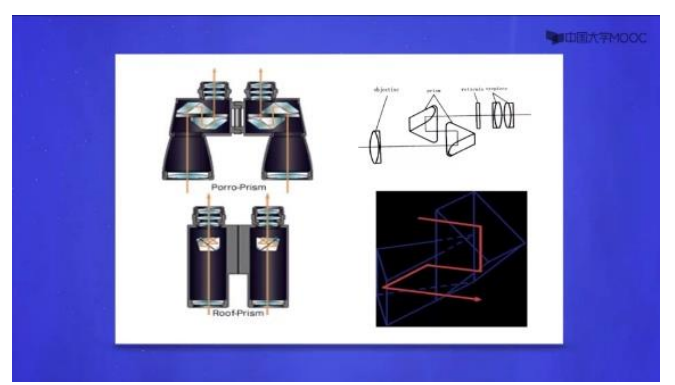

The topics and main contents of the online lecture are shown in Table 3.

Table.3 The topics and contents of the online lecture

\begin{tabular}{|l|l|}
\hline No. & \multicolumn{1}{|c|}{ Topic(contents) } \\
\hline 1 & Principle of image aberrations( definitions, image quality evaluation and measuring methods) \\
\hline 2 & Theories of automatic design(algorithm, introduction of typical software: zemax, code v, etc) \\
\hline 3 & Basic skills to use optical design software-zemax \\
\hline 4 & Traditional optical system design method( Telescope, Microscope, Photographic lens) \\
\hline 5 & $\begin{array}{l}\text { Examples of real-world projects design(Catadioptric Panorama Image System, Off-axis mirror system, } \\
\text { Endoscope lens, Multi-spectral infrared optical system, LED system) }\end{array}$ \\
\hline 6 & Fabrication and Testing Technology of the Optical Elements \\
\hline
\end{tabular}

Besides the topics, useful reference documents such as glass catalog are also released on the web. Students can choose what they want to learn according to their different requirements. At the same time, we opened the discussion board online. Every learner can raise their interest topics or their questions to discuss online with other learners or teachers. 


\subsection{Integrating Informatization into teaching}

Although the MOOC includes almost all the necessary contents of optical system design, our main goal is to integrate the online resources into our regular course teaching. We modified our teaching course schedule in Table 2 . The content of Introduction of optical system design software, which can be got from MOOC, was completely moved away from the class. The other lecture parts were also reduced under the support from online teaching resources.

When the teachers give lectures in class, they act just like a learning guide. They will give a brief introduction of the contents, explain the learning objectives, and ask the students to get more detailed information from MOOC after class. In this way, the saved class hours can be used to focus on the effective discussion about the design methods for the real projects, assist the students to solve independent problems in labs. In the MOOC part, students can choose any topics at any time for deep study, or for getting instructions to use software and practice typical system design. In this way, the class has been extended and developed both in times and spaces while the advantages of class teaching mode were kept simultaneously.

\subsection{Students' work and feedbacks}

Following the modified course schedule, we have integrated informatization online resources with our class-lab teaching for 2 years. The results are encouraging when we saw most of our students finished their excellent design work. As beginners in optical system design area, our students has revealed their great capability of learning and real-problem solving. Some pictures of their designs and their working process are shown in Figure 2.
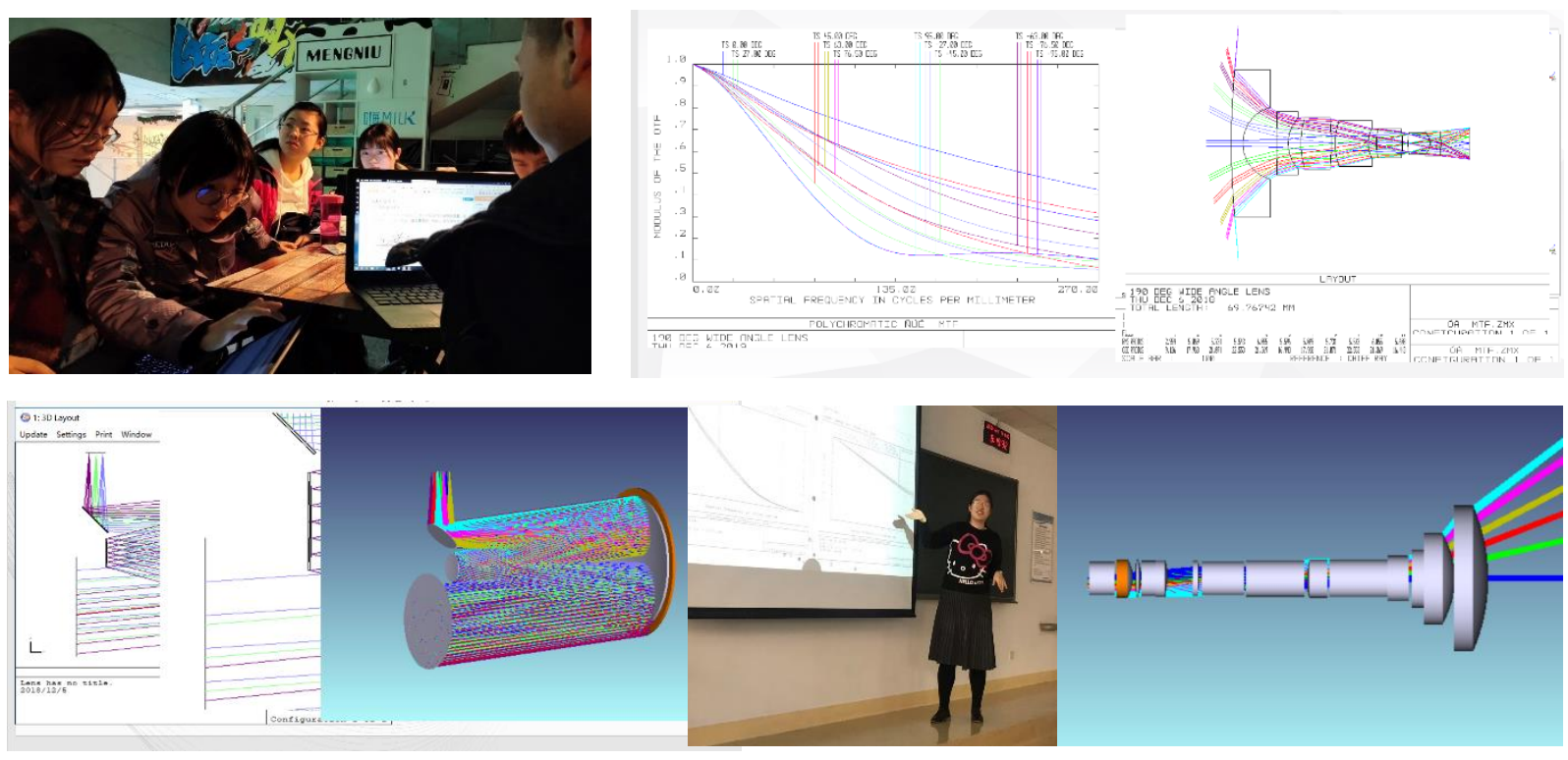

Figure 2. Pictures of students' design work and working process

We also conducted a survey among 36 students in a class for the effects of our trial at the end of the course last semester. Students were asked to do self-rating for their own ability to make a real-world project design. We also gave them a list of different teaching ways/methods we used in the course and asked them to choose the factors helping them most. Figure 3 shows the result of the survey based on students' feedbacks.

From the figure, we can see more than $80 \%$ of the students gave themselves a score over 80 , which means a high achievement in this course. we can also see $83 \%$ of the students chose informatization as one of the most helpful ways in their study. Anyway, we should notice there are still a few students who did not benefit from such a blended teaching and learning mode. This will remind us to explore a better integration of different teaching ways in our next trial. 

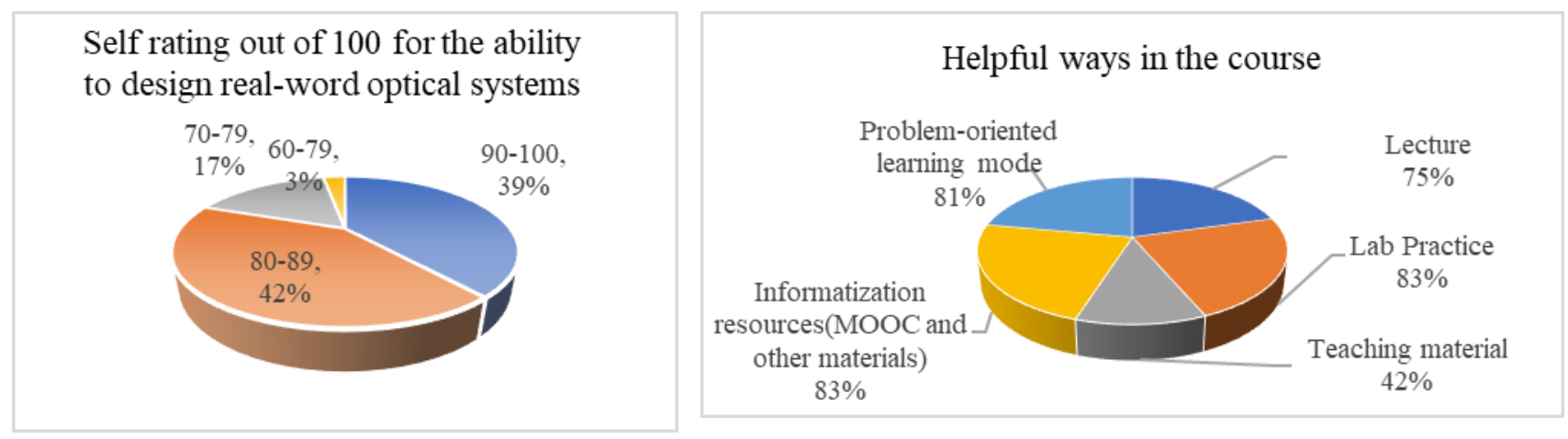

Figure 3. Statistics of students' feedback

\section{CONCLUSIONS}

The integration of informatization resources and traditional teaching is an effective way to carry out problem-based teaching and learning in engineering education. We have got positive results from our trial in the course of Optical System Design. Since we are still in the start stage, there is much space left to be improved. A better matching between the online and the in-class teaching contents, the reasonable time distribution, the effective supervision and evaluation for the online learning are all important issues to be considered next. We will try to make our teaching model more scientific and efficient. In this way, students can gain the knowledge better and enhance their ability to solve problems.

\section{REFERENCES}

[1] Jacqueline Wong,Martine Baars,et al., "Supporting Self-Regulated Learning in Online Learning Environments and MOOCs, A Systematic Review”, International Journal of Human-Computer Interaction, Vol. 35,356373(2019)

[2] Albelbisi, N.A., "The role of quality factors in supporting self-regulated learning (SRL) skills in MOOC environment", Education Information Technologies, Volume 24, 1681-1698(2019)

[3] nés Gil-Jaurena,Daniel Domínguez, “Teachers' roles in light of massive open online courses (MOOCs): Evolution and challenges in higher distance education",International Review of Education, Vol 64, Issue 2, pp 197-219(2018)

[4] Ya Zhou, Yao Hu et al. "Why not serve an educational buffet for students? Blended learning in optics experimental education", Proc. SPIE 10452, 14th Conference on Education and Training in Optics and Photonics: ETOP 2017, 1045210 (16 August 2017) 